\title{
Inheritance and identification of molecular markers associated with spot blotch (Cochliobolus sativus L.) resistance through microsatellites analysis in barley
}

\author{
Tyagi Kuldeep ${ }^{1}$, Rajiv Nandan ${ }^{1}$, Uttam Kumar ${ }^{1}$, Lal Chand Prasad ${ }^{1}$, Ramesh Chand ${ }^{2}$ and Arun Kumar Joshi ${ }^{1}$ \\ ${ }^{1}$ Department of Genetics and Plant Breeding, Institute of Agricultural Sciences, Banaras \\ Hindu University, Varanasi, UP, India. \\ ${ }^{2}$ Department of Mycology and Plant Pathology, Institute of Agricultural Sciences, \\ Banaras Hindu University, Varanasi, UP, India.
}

\begin{abstract}
Spot blotch resistant (IBON 18) and susceptible (RD 2508) lines were crossed to investigate inheritance of resistance and to identify simple sequence repeats (SSRs) associated with resistance. $F_{1}$ resistance was intermediate and suggested additive nature of inheritance. Three additive genes was noted in the distribution of $F_{3}, F_{4}$ and $F_{5}$ generations. In $F_{6}$ and $F_{6-7}$, the quantitative and qualitative approaches also suggested the control of three resistance genes. The parents and the RILs $\left(F_{6} / F_{6-7}\right)$ were grown in four environments and spot blotch severity recorded. Forty five SSR primers, specific for chromosomes $1(7 \mathrm{H})$ and $5(1 \mathrm{H})$, were applied. Of these, 12 were polymorphic between the parents, and between the resistant and susceptible bulks. Three markers BMS 32, BMS 90 and HVCMA showed association with resistance, which was further confirmed through selective genotyping. The co-segregation data on the molecular markers (BMS 32, BMS 90 and HVCMA) and spot blotch severity on 173 RILs was analyzed by single marker linear regression approach. Significant regression suggested linkage among BMS 32, BMS 90 and HVCMA and the three resistant genes (designated as $R c s-q t /-5 H-1, R c s-q t /-5 H-2$ and $R c s-q t-1 H-1$.) respectively. These markers explained $28 \%, 19 \%$ and $12 \%$ of variation respectively, for spot blotch resistance among the RILs.
\end{abstract}

Key words: microsatellite markers, molecular marker, spot blotch, Cochliobolus sativus, barley.

Received: September 12, 2007; Accepted: April 15, 2008.

\section{Introduction}

Spot blotch of barley caused by Cochliobolus sativus (Ito and kurib.) Drechsl. ex Dastur Bipolaris sorokiniana (Sacc in sorok.) Shoem. Helminthosporium sativum Pamm, King and Bakke is responsible for yield and quality reductions in many parts of the world (Piening et al., 1976; Nutter et al., 1985). In susceptible barley cultivars, average yield losses of 16\%-33\% have been reported (Clark, 1979). In Syria, Van Leur (1991) reported a 40\% yield loss in barley due to infection by $C$. sativus. Low resistance to spot blotch in barley cultivars of south Asia causes significant recurring losses to small farmers and recently breeding for spot blotch resistance has assumed significant importance in south Asia.

Several attempts have been made to control spot blotch but no single control measure has been successful.

Send correspondence to Arun K. Joshi. Department of Genetics and Plant Breeding, Institute of Agricultural Sciences, Banaras Hindu University, 221005 Varanasi, UP, India. E-mail: joshi_vns@ yahoo.co.in
Hence similar to wheat, an integrated approach (Joshi and Chand, 2002) with host resistance as a major component is considered necessary. Inheritance studies on resistance to spot blotch of barley are available but the nature of inheritance still appears to be debatable. Reports indicate presence of monogenic (Arny, 1951; Wilcoxson et al., 1990) and polygenic (Griffee, 1925; Steffenson et al., 1996) types of resistance. Steffenson et al. (1996) reported that in barley, different genes control spot blotch resistance at seedling and adult stage. Reports on inheritance of spot blotch resistance using South Asian barley lines is completely lacking. Barley lines with higher levels of resistance are difficult to achieve owing to the influence of environment on disease development (Wilcoxson et al., 1990; Bailey and Wolf, 1994) and the quantitative nature of resistance (Cohen et al., 1969; Kutcher et al., 1994). A clear information regarding inheritance of spot blotch resistance is needed to design suitable strategies to enhance resistance of barley cultivars.

The conventional methods to select resistance genotypes by inoculating plants with spot blotch isolates are 
time consuming, laborious, destructive and are not always reliable because of substantial environmental influence. The number of lines to phenotype can be substantially reduced (and so the cost) by identifying markers that are closely linked to the gene of interest. However, in spot blotch of barley, it would be important to confirm that the progeny of a new cross between the resistant (linked to the marker) and the new susceptible genotype has (in addition to the marker) the resistance phenotype due to possible epistatic or modifying effects (Bilgic et al., 2005). Polymerase chain reaction (PCR) based markers, such as microsatellite (SSRs) (Condit and Hubble, 1991), can reduce the cost of identifying genetic markers and allow large scale genotyping of individuals at any location. The process of identification of molecular markers linked with traits of interest has become more efficient by the use of Bulk segregant analysis (BSA) (Michelmore et al., 1991).

Development of genotype resistant to spot blotch poses serious challenge to the barley breeders. A clear information regarding the inheritance of spot blotch resistance and availability of molecular markers linked to the resistance genes are needed to design suitable strategies to enhance resistance of barley cultivars. Reports on the inheritance and molecular markers of spot blotch resistance in South Asian genotypes is almost non-existent. Therefore, the present study was initiated with two objectives: (i) investigate the inheritance pattern of resistance in the barley accession IBON 18 to spot blotch, and (ii) identify SSR markers associated with spot blotch resistance in the $F_{6}$ population of a cross between IBON 18 and RD 2508 to assist barley breeding in South Asia for greater resistance against spot blotch.

\section{Materials and Methods}

\section{Plant materials and development of segregating progenies}

Single plant selections of resistant (IBON 18) and susceptible (RD 2508) genotypes were multiplied and used in the cross. Resistant parent IBON 18 (a germplasm line introduced form ICARDA/CIMMYT) was crossed with the susceptible RD 2508 (RD 2035/PG 90) which is otherwise higher yielding with good agronomic performance. Parents and $F_{1}$ progenies were evaluated for resistance to spot blotch under an induced epiphytotic obtained in the field at Varanasi (North Eastern Plains Zone, India, $25.2^{\circ} \mathrm{N}$ and 83. $0^{\circ} \mathrm{E}$ ) in the year 1999-00 and 2003-04. Plots (ca. 60-70 plants) of $F_{1}$ generation consisted of two 2-m rows seeded $25 \mathrm{~cm}$ apart with $30 \mathrm{~cm}$ between plots. The susceptible barley genotype RD 2503 was planted in alleys and borders, two weeks before sowing the experiment to enhance the spread of inoculums.

The progenies of the cross were advanced to the $\mathrm{F}_{3}$, $\mathrm{F}_{4}, \mathrm{~F}_{5}$ and $\mathrm{F}_{6}$ generations following the method described by Singh and Rajaram (1991) and Joshi et al. (2002, 2004a) where a random plant in each generation from each line was harvested for advancing the generation. $\mathrm{F}_{3}$ lines were obtained from around 200 randomly chosen space planted $F_{2}$ plants grown in the summer crop season (2000) at the off-season nursery, Wellington, Tamil Nadu. Half of the seeds of the $F_{2}$ plants were advanced to obtain $F_{3}$ generation. The $\mathrm{F}_{3}$ lines at the off-season nursery were harvested to obtain $\mathrm{F}_{4}$ families. The $\mathrm{F}_{3}$ and $\mathrm{F}_{4}$ lines were evaluated under induced epiphytotic conditions during crop season 2001-02. In both generations, plots of each line consisted of a single $3 \mathrm{~m}$ row with $30 \mathrm{~cm}$ space between the plots and maintaining around $40-50$ plants per row. Sowing was done in the second fortnight of November in order to allow the post anthesis stage to coincide with the relatively warm temperature occurring in March which favors disease development and spread.

In the next crop season (2002-03), 183 progeny lines of $F_{5}$ were evaluated under induced epiphytotic conditions at Varanasi. In the $F_{6}$ generation, 173 progeny lines were planted in two dates of sowings (third week of November and first week of December) in the year 2003-04. Other details of planting were as described for $\mathrm{F}_{3}, \mathrm{~F}_{4}$ and $\mathrm{F}_{5}$ generations. However, based on the number of days to maturity of the RILs observed in the $\mathrm{F}_{5}$ generation, differential sowings were carried out in the $F_{6}$ generation to synchronize the growth stages between progeny rows, thereby attempting to nullify the growth stage $\mathrm{x}$ disease severity interaction. To further confirm the number of genes controlling resistance, the $\mathrm{F}_{6-7}$ RILs were also evaluated in the year 2004-2005 in two dates of sowings (third week of November and first week of December) following the approach described for previous generation.

\section{Inoculation procedure and disease assessment}

Spot blotch disease was induced by inoculating spreader rows and a pure culture of the locally most aggressive isolates of $B$. Sorokiniana (Isolates No. RCBHUBR1857) identified at this center. The isolate was multiplied on barley grains and spores were harvested in water (Misra, 1973). A spore suspension (approximately $10^{4}$ spores $/ \mathrm{mL}$ ) containing the surfactant Tween 20 , was uniformly sprayed by using a hand held atomizer at three stages: tillering, flag leaf emergence and anthesis during the evening hours (Joshi et al., 2007b, c).

Disease was measured using spot blotch severity (\%) for each genotype such that genotypes that scored less than 30 were considered resistant, between 40 and 50 as moderately resistant; between 60 and 70 as moderately susceptible, and those having higher than 80 as susceptible (Joshi et al., 2007a, b). Spot blotch level was assessed five times; at growth stages 55 (half of inflorescences emerged), 60 (beginning of anthesis), 65 (anthesis half complete), 73 (early milk) and 77 (late milk) (Zadoks et al., 1974). For each line, the disease scores of all the plants, including the most susceptible and most resistant ones, were recorded. For each 
scoring date, growth stage was also recorded. Area Under Disease Progress Curve (AUDPC) estimates were based on the plot disease severities at different growth stages (van der Plank, 1963). The lines that showed AUDPC $(<500)$ were considered resistant and the lines that showed AUDPC ( $>2000)$ were considered susceptible.

Following formula was used for calculating AUDPC.

$$
\mathrm{AUDPC}=\sum_{i=1}^{n}\left[\frac{Y_{i}+Y_{i+1}}{2} \times\left(t_{i+1}-t_{i}\right)\right]
$$

where $Y_{i}=$ disease level at time $t_{i} ; t_{(i+1)}-t_{i}=$ time (days) between two disease scores; $n=$ number of dates on which spot blotch was recorded.

\section{Estimation of number of genes}

To estimate the number of segregating genes in each cross, $\mathrm{F}_{3}$ lines were grouped in to three classes, (i) homozygous for the resistant parental response, (ii) homozygous for the susceptible parental response, and (iii) segregating or homozygous different than the parents. In the $\mathrm{F}_{4}, \mathrm{~F}_{5}$ and $\mathrm{F}_{6} / \mathrm{F}_{6-7}$ generations, lines were grouped into three classes (Singh and Rajaram, 1991, Joshi et al., 2007a) by merging the last two categories. The observed and expected distributions of $\mathrm{F}_{3}, \mathrm{~F}_{4}, \mathrm{~F}_{5}$ and $\mathrm{F}_{6} / \mathrm{F}_{6-7}$ lines in disease severity categories were tested by $\chi^{2}$ analysis. To confirm the number of genes obtained by $\chi^{2}$ analysis, a quantitative approach (Wright, 1968) was also followed in the $\mathrm{F}_{6} / \mathrm{F}_{6-7}$ generations. In this method the number of genes controlling spot blotch resistance was verified using the formula (Singh et al., 1995; Joshi et al., 2007a), $n=(G R)^{2} / R \times \sigma^{2} g$, where $n=$ minimum number of genes, $G R=$ genotypic range, $\sigma^{2} g=$ genetic variance of the segregating generation, and the factor $\mathrm{R}=4.13$ in case of $\mathrm{F}_{6}$ generation. GR was estimated by two different methods (Singh and Rajaram, 1995; Joshi et al., 2007a). In the first method GR was the range of segregating generation line means, while in the second method GR was the range of segregating generation line means multiplied by heritability. Heritability was used in the second method to eliminate the influence of environment on the expression of the disease severity (Mulitze and Baker, 1995).

Analysis of variance was conducted following split plot analysis of the data of four environments of two years (2003-04 and 2004-05) using SAS software (SAS Institute, 1997) to determine the differences for spot blotch severities among the $F_{6} / F_{6-7}$ lines. Narrow sense heritability was estimated using the entry mean formula given by Fehr (1987): $h^{2}=$ genotypic variance/phenotypic variance; genotypic and phenotypic variances were estimated from the ANOVA table following Comstock and Moll (1963). Although the genetic variance used in the formula to calculate heritability was the total genetic variance of the segregating generation lines, the heritability estimate was considered to be the narrow-sense because dominance variance was neg- ligible and the confounding effect of the additive-by-additive genetic variance could be included in the heritability estimate at the level of inbreeding (Singh and Rajaram, 1995). Phenotypic correlation coefficients of spot blotch severity and AUDPC values among four environments (6 pair-wise combinations) were also calculated using SAS software (SAS, 1997).

\section{DNA isolation and bulked segregant analysis}

Leaves were harvested from 15 days old seedlings from the RILs $\left(\mathrm{F}_{6}\right)$ in the icebox from the field. Genomic DNA was isolated from the seedling leaves using CTAB method described by Saghai-Maroof et al. (1984). DNA concentration was determined through spectrometer and quality of DNA was checked by agarose gel electrophoresis $(0.8 \%)$. After quantification, the DNA was diluted to a concentration of $30 \mathrm{ng} / \mu \mathrm{L}$ using Tris-EDTA buffer $(10 \mathrm{mM}$ Tris, $0.1 \mathrm{mM}$ EDTA, pH 8). DNA from the six to seven most resistant RILs which had disease severity lower than $25 \%$ and AUDPC $>500$ was pooled at an equal amount to create the resistant DNA bulk. Care was taken to ensure that these RILs possessed similar days to maturity and plant height to avoid the effect of plant growth stages on proper phenotyping of the lines. Similarly, DNA from the six to seven most susceptible RILs, which has disease severity higher than $85 \%$ and AUDPC greater than 2000, was pooled to create the susceptible bulk.

\section{SSR markers}

Forty five SSRs primers (Table 1), based on the map of Becker and Heun (1995), Liu et al. (1996), Ramsay et al. (2000) and Li et al. (2003), specific for $1 \mathrm{H}$ and $5 \mathrm{H}$ were used to screen for polymorphism between IBON 18 and RD 2508. Then the polymorphic markers were screened against the two DNA bulks. When the markers were found polymorphic between DNA bulks, they were screened with all 173 lines ( $\mathrm{F}_{6}$ generation) of the 'IBON $18 \times$ RD2508'.

PCR reactions were performed as described by Ramsay et al. (2000) with minor modifications such that the reaction volume was reduced to $18 \mu \mathrm{L}$. DNA amplification was carried out in a 20 well thermocycler (TECHNE, England) each containing 50-100 ng template DNA, $0.2 \mu \mathrm{M}$ of each primer, $200 \mu \mathrm{M}$ of each of the dNTPs, $2.5 \mathrm{mM} \mathrm{MgCl}_{2}$, $1 \mathrm{X}$ PCR buffer and 1U of Taq DNA Polymerase (Bangalore Genei, India; The composition for $10 \mathrm{x}$ buffer was $=100 \mathrm{mM}$ Tris- $\mathrm{HCl}, \mathrm{pH} 8.3$ at $25^{\circ} \mathrm{C} ; 500 \mathrm{mM} \mathrm{KCl}$; $15 \mathrm{mM} \mathrm{MgCl}_{2} ; 0.5 \%$ (vol) Tween 20). The temperature profile for annealing was used according to the information provided for the primers (Becker and Heun, 1995; Liu et al., 1996; Ramsay et al., 2000; Li et al., 2003) (Table 1). The amplification products were separated on $2.5 \%$ agarose gels with TBE buffer (100 mM Tris-borate, $2.5 \mathrm{mM}$ EDTA, pH 8). The gels were stained with ethidium bromide, viewed under an ultraviolet transilluminator and then photographed. Single marker QTL analysis using linear re- 
gression was performed following the method of Nelson (1997). The marker allele $s r$ (spot blotch resistant allele) was coded 1 and the allele ss (spot blotch susceptible allele) were coded 0 for conducting regression analysis. Genetic linkage analysis for SSRs was performed using MAP-

Table 1 - List of primers for chromosome 1 and 5 of barley used for finding SSR markers for spot blotch resistance.

\begin{tabular}{|c|c|}
\hline Chromosome 1 & Chromosome 5 \\
\hline HVWAXY & BMS 02 \\
\hline HVCMA & BMS32 \\
\hline HVM 5 & BMS 90 \\
\hline HVM 4 & HVM 20 \\
\hline HVM 49 & HVM 43 \\
\hline HVM 51 & HVM 63 \\
\hline Bmac 0063 & HVM 64 \\
\hline Bmac 0032 & HVM 70 \\
\hline Bmac 0399 & GBMS 63 \\
\hline Bmac0213 & GBMS 60 \\
\hline EBmac 0783 & GBM 68 \\
\hline GBMS 12 & GBMS 70 \\
\hline GBMS 37 & GBMS 75 \\
\hline GBMS 53 & GBMS 106 \\
\hline GBMS 54 & GBMS 115 \\
\hline GBMS 62 & GBMS 119 \\
\hline GBMS 65 & GBMS 156 \\
\hline GBMS 93 & GBMS 174 \\
\hline GBMS 143 & GBMS 196 \\
\hline GBMS 187 & GBMS 219b \\
\hline \multicolumn{2}{|l|}{ GBMS 219a } \\
\hline \multicolumn{2}{|l|}{ Bmag 0382} \\
\hline \multicolumn{2}{|l|}{ Bmag 0154} \\
\hline \multicolumn{2}{|l|}{ Bmag 0579} \\
\hline Bmag 0345 & \\
\hline
\end{tabular}

MAKER ver. 3.0 (Lander et al., 1987), with a LOD score of 3.0. Recombination frequencies were transformed to centiMorgans (cM) using the formula of Kosambi (1944).

\section{Results}

\section{Inheritance of spot blotch}

Compared with parents, the spot blotch scores of the $F_{1}$ (Table 2) appeared to be intermediate, indicating the absence of dominance for the genes governing resistance. This was also suggested by the AUDPC distribution (Figure 1), which has been suggested to be an appropriate parameter to distinguish the resistance of genotypes (van der Plank, 1963). The $\mathrm{F}_{3}$-line distributions in cross (Figure 1, Table 3) indicated that resistance genes interacted in an additive manner. Very few lines showed a response similar to the resistant or the susceptible parent. In the $\mathrm{F}_{3}$ progeny rows, the test of goodness of fit suggested segregation at three independent loci (Table 3). As with the $\mathrm{F}_{3}$ generation, lines having responses similar to the parental types were found to be at a low frequency in the $\mathrm{F}_{4}, \mathrm{~F}_{5}$ as well as the $\mathrm{F}_{6}$ generations (Table 3). For these generations, these test for goodness of fit also indicated the presence of three genes for resistance (Table 3).

The heritability for the spot blotch severity in the four environments ( $F_{6}$ date $I, F_{6}$ date II, $F_{6-7}$ date I and $F_{6-7}$ date II) was moderately high and ranged from $76-83 \%$. The number of resistance genes obtained from the quantitative analysis (Table 4) showed that gene numbers in the resistant genotype were close to three as obtained in the test of goodness of fit. The distribution of $F_{6}$ lines (Figure 2) also suggested the role of polygenes in controlling resistance.

\section{ANOVA analysis}

The mean disease severity (\%) of RILs ranged from $5.0 \%$ (Environment I and IV) to $96.8 \%$ (Environment I) showing large phenotypic variation in the population. Analysis of variance showed significant variation among the RILs. RIL $x$ environment interaction was also found significant. The six possible combinations of the ranks of RILs in four environments arranged in pairs displayed positive and significant correlations (0.648-0.903) for both dis-

Table 2 - Mean percentage spot blotch scores and AUDPC with standard errors for resistant and susceptible parents, as well as $\mathrm{F}_{1}$ used in the genetic analysis.

\begin{tabular}{lccccc}
\hline \multirow{2}{*}{$\begin{array}{l}\text { Parents } \\
\text { and } \mathrm{F}_{1}\end{array}$} & \multicolumn{3}{c}{ Mean disease response to spot blotch } \\
\cline { 2 - 3 } & \multicolumn{2}{c}{ \% Severity $^{\mathrm{a}}$} & & \multicolumn{2}{c}{ AUDPC } \\
\cline { 2 - 3 } \cline { 5 - 6 } & $2000-01$ & $2004-05$ & & $2000-01$ & $2004-05$ \\
\hline IBON18 & $10.67 \pm 3.9$ & $12.92 \pm 4.7$ & & $2520.51 \pm 83.5$ & $2410.3 \pm 93.1$ \\
RD5208 & $89.16 \pm 4.2$ & $92.58 \pm 4.2$ & & $463.75 \pm 83.7$ & $418.7 \pm 88.8$ \\
IBON 18 (R) X RD 2508 (S) & $45.67 \pm 2.9$ & $49.17 \pm 3.0$ & & $1148.7 \pm 55.5$ & $1212.5 \pm 63.7$ \\
\hline
\end{tabular}

${ }^{\mathrm{a}}$ Final disease scoring at late milk stage (Zadoks scale 77). 


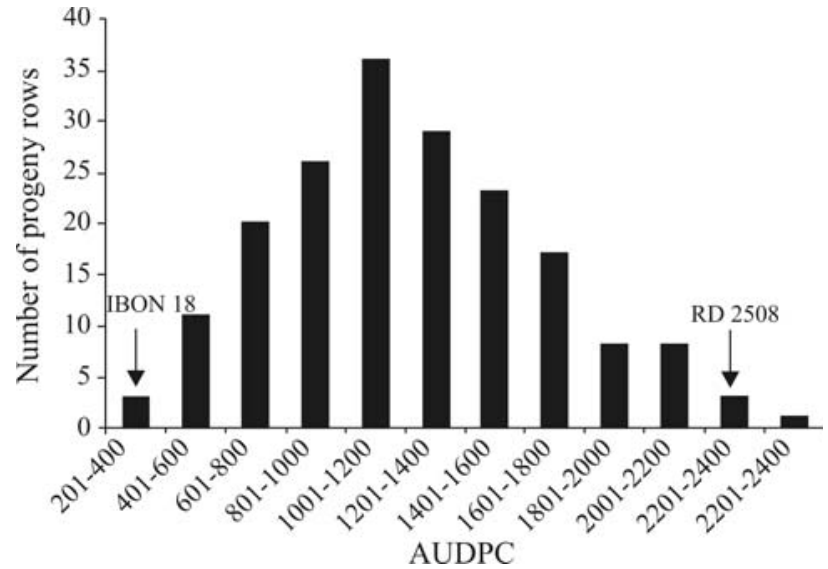

Figure 1 - Distribution of AUDPC of $F_{3}$ lines of the cross resistant (IBON 18) x susceptible (RD 2508) for spot blotch severity in barley.

ease severity (\%) and AUDPC values. The most resistant and susceptible lines correlated more highly than the intermediate lines. For the two extremes, i.e., the six most resistant and six most susceptible RILs which were used to constitute the bulk, the correlation in the six environments ranged from 0.93 to 0.96 .

\section{SSR analysis}

Out of a total of $45 \mathrm{SSRs}$ primer pairs used, 12 $(26.6 \%)$ primer pairs detected reproducible polymorphism between the parental genotypes. Bulked segregant analysis (Michelmore et al., 1991) using these 12 primers showed that three markers, BMS 32, BMS 90 and HVCMA displayed an amplification profile characteristic of resistant and susceptible parent in the corresponding bulks. This suggested an association of these markers with spot blotch resistance. Selective genotyping (Lander and Botstein, 1989) of individual RI lines belonging to the two bulks suggested an association between the BMS 32, BMS 90 and HVCMA markers and spot blotch resistance (Figures 3 and 4). The three SSRs markers had the following primer sequence: BMS 32: forward primer GGATCAAAGTCCG GCTAG, reverse primer TGCGGGCCTCATACTGAC, BMS 90: forward primer ACATCAACCCTCCTGCTC, reverse primer CCGCACATAGTGGTTACATC, and HVCMA: forward primer GCCTCGGTTTGGACATATA AAG, reverse primer GTAAAGCAAATGTTGAGCAA CG (Ramsay et al., 2000 and Li et al., 2003). Subsequently, all (173) $F_{6}$ RI lines were genotyped using the three markers and data on segregation of the marker were recorded for conducting QTL analysis.

The regression of spot blotch severity on the BMS 32, BMS 90 and HVCMA markers were highly significant indicating close association between molecular markers and resistance for spot blotch (designated as Rcs-qtl-5H-1, Rcs-qtl-5H-2 and Rcs-qtl-1H-1). The two genes (Rcs-qtl$5 H-1, R c s-q t l-5 H-2)$ were located on chromosome $5 \mathrm{H}$,

Table 3 - Goodness of fit of ratios observed and hypothesized class frequencies for $\mathrm{F}_{3}, \mathrm{~F}_{4}, \mathrm{~F}_{5}, \mathrm{~F}_{6}$ and $\mathrm{F}_{6-7}$ lines from the cross between resistant (IBON 18) and susceptible (RD 2508) parents.

\begin{tabular}{lccccccc}
\hline Generation & Resistant $^{1}$ & Segregating $^{2}$ & Susceptible $^{3}$ & Hypothesized ratio $^{2}$ & $\chi^{2}$ value & p-value & Gene number \\
\hline $\mathrm{F}_{3}$ & 3 & 176 & 4 & $1.56: 96.87: 1.56$ & 1.54 & 0.27 & 3 \\
$\mathrm{~F}_{4}$ & 9 & 167 & 7 & $5.27: 89.45: 5.27$ & 2.29 & 0.32 & 3 \\
$\mathrm{~F}_{5}$ & 15 & 159 & 9 & $8.37: 83.25: 8.37$ & 1.64 & 0.44 & 3 \\
$\mathrm{~F}_{6}$ (Date I) & 21 & 133 & 19 & $10.30: 79.40: 10.30$ & 0.42 & 0.81 & 3 \\
$\mathrm{~F}_{6}$ (Date II) & 20 & 131 & 22 & $10.30: 79.40: 10.30$ & 0.14 & 0.93 & 3 \\
$\mathrm{~F}_{6-7}$ (Date I) & 22 & 133 & 18 & $10.30: 79.40: 10.30$ & 0.70 & 0.71 & 3 \\
$\mathrm{~F}_{6-7}$ (Date II) & 23 & 128 & 22 & $10.30: 79.40: 10.30$ & 0.19 & 0.94 & 3 \\
\hline
\end{tabular}

${ }^{1}$ Homozygous for resistant parental type (homozygous for all the resistant alleles. ${ }^{2}$ Segregating or homozygous for disease levels different from parental level. ${ }^{3}$ Homozygous for susceptible parental type (homozygous lacking all the resistant alleles).

Table 4 - Estimate of maximum number of effective genes contributing to spot blotch resistance in crosses between IBON18 x RD 2508 using Wright's (1968) formula modified for $\mathrm{F}_{6}$ generation (Singh et al., 1995) in four environments.

\begin{tabular}{|c|c|c|c|c|c|}
\hline \multirow[t]{3}{*}{ Generation } & \multirow[t]{3}{*}{ Environment } & \multicolumn{4}{|c|}{ Number of genes } \\
\hline & & \multicolumn{2}{|c|}{ Disease severity (\%) } & \multicolumn{2}{|c|}{ AUDPC } \\
\hline & & Method I & Method II & Method I & Method II \\
\hline $\mathrm{F}_{6}$ (Date I) & 2003-04 (I) & 3.98 & 2.39 & 4.27 & 2.67 \\
\hline $\mathrm{F}_{6}$ (Date II) & 2003-04 (II) & 3.74 & 2.27 & 4.14 & 2.79 \\
\hline $\mathrm{F}_{6-7}$ (Date I) & 2004-05 (I) & 4.31 & 2.52 & 4.61 & 2.93 \\
\hline $\mathrm{F}_{6-7}$ (Date II) & 2004-05 (II) & 3.34 & 2.14 & 3.85 & 2.65 \\
\hline
\end{tabular}




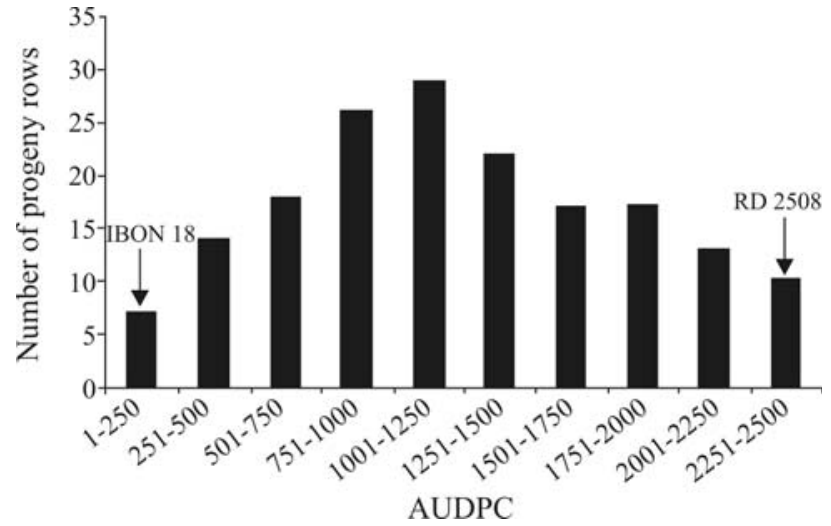

Figure 2 - Distribution of AUDPC of $\mathrm{F}_{6}$ lines of a cross between resistant (IBON 18) and susceptible (RD 2508) for spot blotch during 2003-2004.

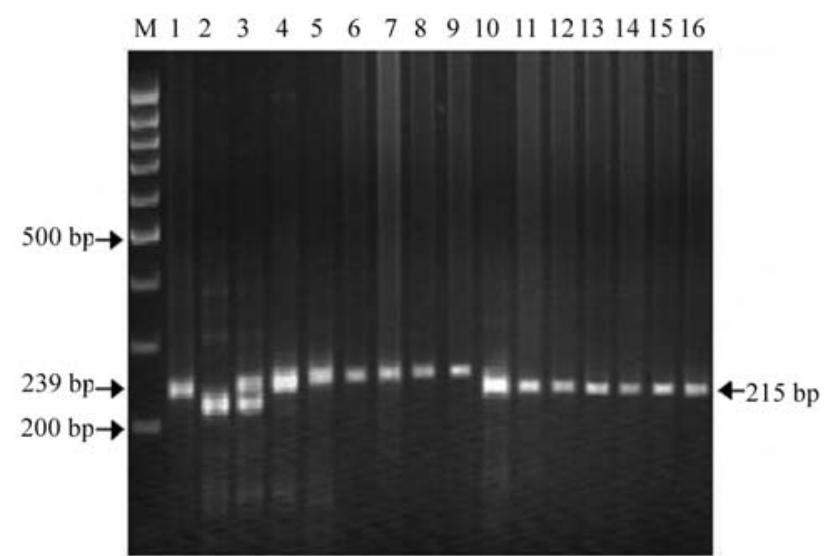

Figure 3 - Selective genotyping of RILs (representing extreme groups) for spot blotch resistance in barley using BMS 32 SSRs primer; Lane $\mathrm{M}=100$-bp ladder marker; 1 = Resistant parent (IBON18); 2 = Susceptible parent (RD2508); 3-9= RILs with low disease severity; 10-16 = RILs with high disease severity.

where as the third one (Rcs-qtl-1H-1) was on chromosome $1 \mathrm{H}$ (Table 5). The $\mathrm{R}^{2}$-value suggested that the SSRs markers linked with BMS 32, BMS 90 and HVCMA contributed to $28 \%, 18 \%$ and $12 \%$ of the total variation present for spot blotch resistance among the RILs.

The SSRs marker BMS32, HVCMA and BMS 90 were found to be linked with a distance of $4.4 \mathrm{cM}, 8.4 \mathrm{cM}$ and $12.5 \mathrm{cM}$, respectively from the resistance locus with a LOD score of 18.49, 12.57 and 8.97 respectively (Table 5), suggesting a good linkage between molecular markers and spot blotch resistance gene.

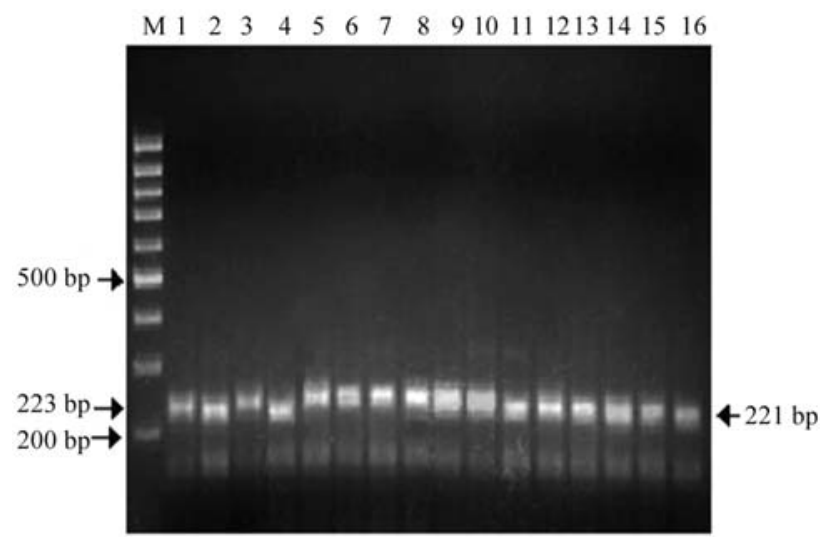

Figure 4 - Selective genotyping of RILs (representing extreme groups) for spot blotch resistance in barley using BMS 90 SSRs primer; Lane $\mathrm{M}=100$-bp ladder marker; 1 = Resistant parent (IBON18); 2 = Susceptible parent (RD2508); 3 = Resistant bulk; 4 = Susceptible bulk; 5-9= RILs with low disease severity; 10-16 = RILs with high disease severity.

\section{Discussion}

The chi square ratios in the four segregating generations suggested that the spot blotch resistance in the barley line IBON 18 was under the control of probably three genes. In case of single gene control, the $\mathrm{F}_{3}$ progeny lines are expected to follow a ratio of $1: 2: 1$. This ratio would be $3: 2: 3$ and $7: 2: 7$ in the $F_{4}$ and $F_{5}$ generations, respectively. As the genes having additive effects will increase, the number of progeny rows similar to parental lines are expected to decrease (Singh and Rajaram, 1995; Joshi et al., 2007a). In all the segregating generations $\left(\mathrm{F}_{3}, \mathrm{~F}_{4}, \mathrm{~F}_{5}\right.$ and $\left.\mathrm{F}_{6}\right)$ of cross IBON 18 X RD 2508, lines with a disease response equivalent to the parental types were in very low frequencies, and the lines were clearly not distributed in a monogenic $(1: 2: 1)$ ratio. The test of goodness of fit suggested segregation at three independent loci.

The inheritance study suggested the role of three genes in controlling resistance to spot blotch in the line IBON 18. The distributions of RILs $\left(F_{6}\right.$ and $\left.F_{6-7}\right)$ for spot blotch AUDPC also suggested polygenic control. Some of the previous studies concerning inheritance of resistance to spot blotch disease of barley also indicated the control by many genes (Griffee 1925; Cohen et al., 1969; Kutcher et al., 1994). However, the quantitative nature of resistance to spot blotch has not been reported in Indian barley cultivars and lines.

Table 5 - SSRs markers, alleles, chromosome locations and map distance.

\begin{tabular}{lccccc}
\hline Marker & Map distance $(\mathrm{cM})$ & LOD & Chromosome & Annealing temp. $\left({ }^{\circ} \mathrm{C}\right)$ & Reference \\
\hline BMS 32 & 4.4 & 18.89 & $5(1 \mathrm{H})$ & 60 & Stein et al., (2007) \\
HVCMA & 8.4 & 12.57 & $1(7 \mathrm{H})$ & 60 & Stein et al., (2007) \\
BMS 90 & 12.5 & 8.97 & $5(1 \mathrm{H})$ & 55 & Stein et al., (2007) \\
\hline
\end{tabular}


The number of effective genes conferring resistance to spot blotch disease in the cross, calculated from the modified formula of Wright (1968), using severity (\%) as well as the AUDPC values, showed almost similar gene numbers in the four environments. The gene numbers were influenced by the measure of the genotypic range used in the formula (Singh and Rajaram, 1995). However, the correction of phenotypic range of the $\mathrm{F}_{6}$ lines by multiplying with heritability (method II) suggested a gene number close to three. In other words, the results were quite similar to that obtained by using $\chi^{2}$ analyses. Hence, it appeared that probably three additive genes are responsible for spot blotch resistance in the barley IBON 18 investigated in the present study. An earlier report (Hosford et al., 1975) suggested polygenic control for spot blotch resistance in which three and four genes were found to control virulence of C. sativus on barley genotypes NDB112 and Larker, respectively. In a study, Griffee (1925) also inferred that three unlinked genes control resistance to spot blotch at the adult plant stage. Bailey et al. (1988) reported a polygenic control for resistance to common root rot caused by Cochliobolus sativus.

The heritability estimates for the $\mathrm{F}_{6}$ and $\mathrm{F}_{6-7}$ generations of the cross were moderately high and ranged from 0.77 to 0.83 across four environments. In an earlier study (Kutcher et al., 1994), the estimate of heritability with respect to spot blotch resistance were reported to be moderate. The spot blotch severity increases with plant maturation (Joshi et al., 2002). Therefore, for best evaluation of resistance of a line or plant, comparison must be done when the disease has just reached maximum severity in the susceptible parent (Joshi et al., 2004b). The additive interactions of only a few (three) genes observed in this study suggested that spot blotch resistance in barley can be realized by growing fairly large segregating populations and selecting for low scoring genotypes at appropriate growth stages under high inoculum pressure. Further, since only a few additive genes were able to display substantially high level of resistance and heritability was moderately high, effective selection could be applied in the early segregation generations as well. For further gains, strong selection pressure could be applied in advanced generations when high homozygosity has been achieved, as also suggested in case of wheat by Joshi et al., (2004a) for spot blotch and Singh and Rajaram (1995) for resistance to scab.

\section{SSR analysis}

In barley, molecular mapping for different traits has been an area of active research, which led to the identification of many markers for several important traits (Steffenson et al., 1996; Tuberosa and Salvi, 2004; Bilgic et al., 2005; Stein et al., 2007). In this study we found that with a large population and precise phenotypic characterization it is possible to detect molecular markers for a trait such as spot blotch resistance that is under polygenic control, even though some loci display large effects. The SSR markers had significant additive effects on spot blotch resistance and appear to display major effect consistently over four environments. These markers were named as QTLs Rcs$q t l-5 H-1, R c s-q t l-5 H-2$ and $R c s-q t l-7 H-1$. The two QTLs, Rcs-qtl-5H-1, Rcs-qtl-5H- 2 contributed to around $28.40 \%$ and $18.97 \%$ variation respectively and were located on chromosome $5(1 \mathrm{H})$. The other QTL Rcs-qtl-7H-1, contributing $12.52 \%$ variation, was found to be located on chromosome $1(7 \mathrm{H})$. Thus, $R c s-q t l-5 H-1$ contributing $28.40 \%$ variation and which was located on chromosome $5(1 \mathrm{H})$ appeared to be a major SSR marker. Steffenson et al. (1996) also reported the presence of the largest QTLs for spot blotch resistance in chromosome $5(1 \mathrm{H})$. A second QTL having lesser magnitude was also mapped in the chromosome $1 \mathrm{H}$. Using microsatellite markers, Mesfin et al. (2003) identified three QTLs for Fusarium head blight on chromosome $2(2 \mathrm{H})$. We mapped microsatellite markers (BMS32, BMS 90 and HVCMA) linked to the spot blotch resistance genes at map distances of $4.4 \mathrm{cM}, 12.5 \mathrm{cM}$ and $8.4 \mathrm{cM}$, respectively. The two QTLs on chromosome 5 $(1 \mathrm{H})$ obtained in the present study contributed a total phenotypic variation of $47.37 \%$ (Rcs-qtl-5H-1 $=28.40 \%$ and $R c s-q t l-5 H-2=18.97 \%$ ) for spot blotch resistance. Since the association of HVCMA located on chromosome $1(7 \mathrm{H})($ Rcs-qtl- $1 H-1)$ explained only $12.52 \%$ of phenotypic variation, we conclude that the marker HVCMA may either be linked to a QTL with a small effect or is loosely linked to a QTL with a large effect (Melchinger, 1998). With moderately high heritability expressed for spot blotch resistance, the markers detected in this study explained around $59.89 \%$ of phenotypic variation.

The identification of three genes that probably control spot blotch resistance and the detection of closely linked markers, should now make marker assisted selection for spot blotch resistance a promising approach in barley. Mapping of additional markers should even result in better genetic resolution and more tightly linked markers for spot blotch resistance genes. Successful MAS and cloning of the major resistance QTLs will crucially depend on the generation of new flanking markers on chromosomes $5 \mathrm{H}$ and $1 \mathrm{H}$.

\section{Acknowledgments}

The authors are grateful to the India Agricultural Research Institute Regional Station, Wellington, Tamil Nadu, for providing off-season facilities.

\section{References}

Arney DC (1951) Inheritance of resistance to spot blotch in barley seedling. Phytopathol 41:691-698.

Bailey KL and Wolf RI (1994) Genetic relationship between reaction to common root rot and yield in the progeny of a barley cross. Can J Plant Pathol 16:163-169.

Bailey KL, Knott DR and Harding H (1988) Heritability and inheritance of resistance to common root rot (Cochlibolus 
sativus) in wheat (Triticum aestivum). Can J Plant Pathol 12:207-214.

Becker J and Heun M (1995) Mapping of digested and undigested random amplified microsatellite polymorphisms in barley. Genome 38:991-998.

Bilgic H, Steffenson BJ and Hayes PM (2005) Comprehensive genetic analyses reveal differential expression of seedling and adult plant resistance to spot blotch in populations of barley. Theor Appl Genet 111:1238-1250.

Clark RV (1979) Yield losses in barley cultivars caused by spot blotch. Canadian J Plant Pathol 1:113-117.

Cohen E, Helgason SB and McDonald WC (1969) A study of factors influencing the genetics of reaction of barley to root rot caused by Helmenthosporium sativum. Can J Bot 47:429443.

Comstock RE and Moll RH (1963) Genotype-environment interaction. In: Hanson WD and Robinson HF (eds.) Statistical Genetics and Plant Breeding. Publ. 982. National Academy of Sciences and National Research Council, Washington DC, pp 164-194.

Condit R and Hubbell S (1991) Abundance and DNA sequence of two-base repeat regions in tropical tree genomes. Genome 34:66-71.

Fehr WR (1987) Principles of Cultivar Development. v. 1. Theory and Technique. Macmillan Publishing Company, New York, $536 \mathrm{pp}$.

Griffee F (1925) Correlated inheritance of botanical characters in barley and the manner of reaction to Helminthosporium sativum. J Agric Res 30:915-933.

Hosford RM, Jr Solangi GRM and Kiesting RL (1975) Inheritance in Cochiliobolus sativus. Phytopathol 65:699-703.

Joshi AK and Chand R (2002) Variation \& inheritance of leaf angle \& its association with spot blotch (Bipolaris sorokiniana) severity in wheat (Triticum aestivum). Euphytica 124:283-291.

Joshi AK, Chand R and Arun B (2002) Relationship of plant height \& days to maturity with resistance to spot blotch in wheat. Euphytica 123:221-228.

Joshi AK, Chand R, Kumar S and Singh RP (2004b) Leaf tip necrosis: A phenotypic marker associated with resistance to spot blotch disease in wheat. Crop Sci 44:792-796.

Joshi AK, Kumari M, Singh VP, Reddy CM, Kumar S, Rane J and Chand R (2007a) Stay green trait: Variation, inheritance and its association with spot blotch resistance in spring wheat (Triticum aestivum L.). Euphytica 153:59-71.

Joshi AK, Ortiz-Ferrara G, Crossa J, Singh G, Alvarado G, Bhatta MR, Duveiller E, Sharma RC, Pandit DB, Siddique AB, et al. (2007b) Associations of environments in South Asia based on spot blotch disease of wheat caused by Cochliobolus sativus. Crop Sci 47:1071-1084.

Joshi AK, Ferrara O, Crossa J, Singh G, Sharma R, Chand R and Parsad R (2007c) Combining superior agronomic performance and terminal heat tolerance with resistance to spot blotch (Bipolaris sorokiniana) in the warm humid Gangetic plains of south Asia. Field Crop Res 103:53-61.

Joshi AK, Kumar S, Chand R and Ortiz-Ferrara G (2004a) Inheritance of resistance to spot blotch caused by Bipolaris sorokiniana in spring wheat. Plant Breeding 123:213-219.

Kosambi DD (1944) The estimation of map diatance from recombination value. Ann Engen 12:172-175.
Kutcher HR, Bailey KL, Rossnagel BG and Legge WG (1994) Heritability of common root rot and spot blotch resistance in barley. Can J Plant Pathol 16:287-294.

Lander ES and Botstein D (1989) Mapping mendilian factors underling quantitative traits using RFLP linkage maps. Genetics 121:185-199.

Lander ES, Green P, Abrahamson J, Barlow A, Daly MJ, Lincoln SE and Newburg L (1987) MAPMAKER: An interactive computer package for constricting primary genetic linkage maps of experimental and natural populations. Genomics 1:174-181.

Li JZ, Sjakste TG, Roder MS and Ganal MW (2003) Development and genetic mapping of 127 new microsatellite markers in barley. Theor Appl Genet 107:1021-1027.

Liu YG, Biyashev RM and Saghai-Maroof MA (1996) Development of simple sequence repeat DNA markers and their integration into a barley linkage map. Theor Appl Genet 93:869-876.

Melchinger AE (1998) Advances in analysis of data on quantitative trait loci. In: Chopra VL, Singh RB and Verma A (eds) Crop Productivity and Sustainability Shaping the Futurex. Oxford and IBH Publ, New Delhi, pp 773-791.

Mesfin A, Smit KP, Dill-Macky R, Evans CK, Waugh R, Gustus D and Muehlbauer GJ (2003) Quantitative trait loci for Fusarium head blight resistance in Barley detected in a two-rowed by six-rowed population. Crop Sci 43:307-318.

Michelmore RW, Paran I and Kesseli RV (1991) Identification of markers linked to disease-resistance genes by bulked segregant analysis: A rapid method to detect the markers in specific genomic regions by using segregating populations. Proc Natl Acad Sci USA 88:9828-9832.

Misra AP (1973) Helminthosporium Species Occurring on Cereals and Other Gramineae. Catholic Press, Ranchi, 289 pp.

Mulitze DK and Baker RJ (1995) Genotype assay and method of moments analyses of five quantitative traits in a spring wheat cross. Crop Sci 25:162-167.

Nelson J (1997) Qgene: Software for marker-based genomic analysis and breeding. Mol Breed 3:239-245.

Nutter FW, Pederson VD and Foster AE (1985) Effect of inoculation with Cochliobolus sativus at specific growth stages on grain yield and quality of malting barley. Crop Sci 25:933938.

Piening LJ, Atkinson TG, Horricks JS, Ledingham RJ, Mills JT and Tinline RD (1976) Barley losses due to common root rot in the prairie provinces of Canada, 1970-1972. Can Plan Dis Surv 56:41-42.

Ramsay L, Macaulay M, Degli Ivanissevich S, Maclean K, Cardle L, Fuller J, Edwards KJ, Tuvesson S, Morgante M and Massari A (2000) A simple sequence repeat-based linkage map of barley. Genetics156:1997-2005.

Saghai-Maroof MA, Soliman KM, Jorgensen RA and RW Allard (1984) Ribosomal DNA spacer length polymorphisms in barley: Mendelian inheritance, chromosomal location, and population dynamics. Proc Natl Acad Sci USA 81:80148018.

SAS (1997) SAS Institute Inc., Cary, NC.

Singh RP and Rajaram S (1991) Genetics of adult-plant resistance to leaf rust in 'Frontana' and three CIMMYT Wheat. Genome 35:24-31. 
Singh RP and Rajaram S (1995) Genetic analysis of resistance to scab in spring wheat cultivar Frontana. Plant Dis 79:138240.

Steffenson BJ, Hayes PM and Kleinhofs (1996) Genetics of seeding and adult plant resistance to net blotch (Pyrenophora teres $f$. teres) and spot blotch (Cochliobolus sativus) in barley. Theor Appl Genet 92:552-558.

Stein N, Prasad M, Scholz U, Thiel T, Zhang H, Wolf M, Kota R, Varshney RK, Perovic D, Grosse I, et al. (2007) A 1,000loci transcript map of the barley genome: New anchoring points for integrative grass genomics. Theor Appl Genet 114:823-839.

Tuberosa R and Salvi S (2004) QTLs and genes for disease resistance in barley and wheat. In: Gupta PK and Varshney RK (eds) Cereal Genomics. Kluwer, The Netherlands, pp 199251.

van Der Plank JE (1963) Plant Diseases: Epidemics and Control. Academic Press, New York, pp 349.
Van Leur JG (1991) Testing barley for resistance to Cochliobolus sativus at ICARDA, Syria. In: Tinline RD (ed) Proceedings of $1^{\text {st }}$ International Workshop on Common Root Rot of Cereals, Saskatoon, pp 128-134.

Wilcoxson RD, Rasmusson DC and Miles MR (1990) Development of barley resistant to spot blotch and genetics of resistance. Plant Dis 74:207-210.

Wright S (1968) Evolution and Genetics of Population. v. I. Genetics and Biometric. University of Chicago Press, Chicago, $469 \mathrm{pp}$.

Zadoks JC, Chang TT and Konzak CF (1974) A decimal code the growth stages of cereals. Weed Res 14:415-421.

Associate Editor: Everaldo Gonçalves de Barros

License information: This is an open-access article distributed under the terms of the Creative Commons Attribution License, which permits unrestricted use, distribution, and reproduction in any medium, provided the original work is properly cited. 